\title{
Identification and Characterization of
} Anthocyanins by High-performance Liquid Chromatography-Electrospray Ionization-Mass Spectrometry in Herbaceous Peony Species

\author{
Ni Jia, Qing-Yan Shu, Dan-Hua Wang, Liang-Sheng Wang ${ }^{1}$, Zheng-An Liu, and Hong-Xu Ren \\ Beijing Botanical Garden, Institute of Botany, the Chinese Academy of Sciences, 20 Nanxincun, \\ Xiangshan, Beijing 100093, China \\ Yan-Jun Xu \\ Department of Applied Chemistry, China Agricultural University, Beijing 100094, China \\ Dai-Ke Tian and Kenneth Michael Tilt \\ Department of Horticulture, Auburn University, Alburn, AL 36849
}

AdDitional Index words. Paeonia, HPLC-ESI-MS ${ }^{\text {n }}$, flower color, galactose, arabinose

\begin{abstract}
Petal anthocyanins were systematically identified and characterized by high-performance liquid chromatography (HPLC)-electrospray ionization-mass spectrometry (MS) coupled with diode array detection among nine wild herbaceous peony (Paeonia $L$.) species (15 accessions). Individual anthocyanins were identified according to the HPLC retention time, elution order, MS fragmentation patterns, and by comparison with authentic standards and published data. Six main anthocyanins, including peonidin-3,5-di- $O$-glucoside, peonidin-3-O-glucoside-5-O-arabinoside (Pn3G5Ara), peonidin-3-O-glucoside, pelargonidin-3,5-di- $O$-glucoside, cyanidin-3,5-di- $O$-glucoside, and cyanidin-3-O-glucoside (Cy3G), were detected. In addition to the well-known major anthocyanins, some minor anthocyanins were identified in herbaceous peony species for the first time. Detection of the unique anthocyanins cyanidin-3-O-glucoside-5-O-galactoside and pelargonidin-3-O-glucoside-5-O-galactoside in both $P a e o n i a$ anomala $\mathrm{L}$. and $P$. anomala ssp. veitchii (Lynch) D.Y. Hong \& K.Y. Pan indicated these two species should belong to the same taxon. Pn3G5Ara was found only in European wild species and subspecies suggesting different metabolic pathways between European and Chinese accessions. Anthocyanins conjugated with galactose and arabinose were observed in the genus Paeonia for the first time. The North American species, Paeonia tenuifolia L., had high Cy3G content in flower petals. This anthocyanin composition is distinct from the anthocyanin composition in Asian and European species and possibly is responsible for the vivid red coloration in flowers.
\end{abstract}

The genus Paeonia consists of three sections (Moutan DC., Onaepia Lindley, and Paeonia DC.) and $\approx 35$ species to form an independent family, Paeoniaceae. Section Paeonia was further divided into two subsections [Foliolatae F.C. Stern and subsection Dissectifoliae F.C. Stern (Stern, 1946)] that were disjunctly distributed in eastern Asia, central Asia, the western Himalayas, and the Mediterranean regions. Section Paeonia is the largest one, consisting of 22 species, some of which are complex and polyploid. Section Paeonia is the evolutional biome in this genus (Ferguson and Sang, 2001; Pan, 1995; Sang et al., 1997).

China is considered to be the distribution and evolution center of the genus Paeonia. The middle region of China is the most concentrated zone of Paeonia species and botanical

\footnotetext{
Received for publication 18 Dec. 2007. Accepted for publication 27 Feb. 2008. This research was supported by the National Natural Science Foundation of China, No. 30771521.

The assistance of De-Yuan Hong (Academician of the Chinese Academy of Sciences) and Da-Ming Zhang (Professor of State Key Laboratory of Systematic and Evolutionary Botany, Institute of Botany, the Chinese Academy of Sciences, Beijing, China) in identifying and providing the wild herbaceous peony species is gratefully acknowledged. We also thank De-Zhong Chen and Fu-Fei Chen of Peace Peony Garden in Lanzhou, Gansu Province, China, for providing the petals of $P$. anomala ssp. veitchii.

${ }^{1}$ Corresponding author. E-mail: wanglsh@ibcas.ac.cn.
}

varieties in the world (Hong et al., 1988; Peng and Jiang, 2000; Yu and Xiao, 1987). Approximately eight species in section Paeonia have been identified as originating from China (Hong et al., 2001). Many primitive, distinct characteristics in this section are unique among angiosperms (Peng and Jiang, 2000).

Chinese herbaceous peony is one of the earliest cultivated plants and the most influential germplasm in the peony population accounting for $41 \%$ of the world's wild germplasm (Gao and Peng, 2004). In the 19th century, Paeonia lactiflora Pallas, the unique wild parent of Chinese cultivars (Yuan, 1999), was introduced into Europe and contributed to many new cultivars by interspecific hybridization with Paeonia officinalis L., a native species of Europe (Wister and Wolfe, 1962). Today, P. lactiflora has become a world-famous flower with many offspring all over the world. In general, the wild species have white and reddish purple flowers, whereas colors of herbaceous peony cultivars are rich in diversity. Cultivars have been divided into nine groups according to petal color: white, yellow, pink, blue, red, purple, black, green, and double color (Li, 1999; Wang, 2003; Wang and Zhang, 2005; Zhang et al., 2006). However, herbaceous peony lacks vivid red color as compared with that of other flowering plants such as tree peony (Paeonia suffruticosa Andrews) and rose (Rosa centifolia $\mathrm{L}$.). 
Anthocyanins are a group of widespread natural pigments in plants that are mainly distributed among flowers, fruit, and vegetables and are responsible for bright colors such as red, purple, and blue. Anthocyanins are composed of anthocyanidin (aglycone) and sugar(s) and one optional component, the acylated group(s). Chemical structures of petal anthocyanins and chemotaxonomy of anthocyanins in tree peony have been studied extensively. In comparison, no comprehensive study of petal anthocyanins of herbaceous peony has been conducted despite its long breeding history and extensive distribution. Only a Japanese research team has made some preliminary studies on color measurement and identification of the flower anthocyanins in four wild Paeonia species $[P$. lactiflora, $P$. tenuifolia, $P$. obovata Maximowicz, and $P$. japonica (Makino) Miyabe \& Takeda] and some Japanese and western herbaceous peony cultivars by thin-layer chromatography (TLC) (Hosoki and Seo, 1991). Six anthocyanins, peonidin-3,5-di-O-glucoside (Pn3G5G), pelargonidin-3,5-di-O-glucoside (Pg3G5G), cyanidin-3,5-di- $O$-glucoside (Cy3G5G), peonidin-3-O-glucoside (Pn3G), cyanidin-3-O-glucoside, and pelargonidin-3-O-glucoside $(\mathrm{Pg} 3 \mathrm{G})$, detected were found to be identical with those of tree peony. However, these results were not comprehensive as judged by TLC (mobility). Use of more highly analytical equipment and more diverse plant material may uncover additional anthocyanins in peony flower petals.

The most effective technique of identifying anthocyanins is by mass spectrometry (Chirinos et al., 2006; Montoro et al., 2006; Zhang and Cheng, 2006). To our knowledge, there have been no published data of anthocyanins in wild herbaceous peony species available. Therefore, the objective of our study was to identify and characterize the anthocyanins in herbaceous peony species from different regions of the world using reverse-phase high-performance liquid chromatography (HPLC) with diode array detection in tandem with electrospray ionization-mass spectrometry $\left(\mathrm{ESI}-\mathrm{MS}^{\mathrm{n}}\right)$ and to clarify the anthocyanin composition. The final results may provide valuable information on the mechanism of their flower coloration and guidelines on breeding new cultivars with novel flower colors in future.

\section{Materials and Methods}

\section{Standards and solvents}

Malvidin-3,5-di- $O$-glucoside (Mv3G5G) was obtained from Extrasynthese (Genay, France). Cy3G5G, Pg3G5G, Pn3G5G, Cy $3 \mathrm{G}, \mathrm{Pg} 3 \mathrm{G}$, and $\mathrm{Pn} 3 \mathrm{G}$ were obtained and identified previously from the Chinese tree peony cultivar Qing Long Wo Mo Chi and a Japanese tree peony cultivar Hohki (Wang et al., 2001a; Zhang et al., 2007). Rutin was purchased from the National Institute for the Control of Pharmaceutical and Biological Products (Beijing, China). Acetonitrile and methanol were HPLC grade. Methanol, acetic acid, trifluoroacetic acid, phosphoric acid, and formic acid were analytical reagent grade. HPLC-grade water (deionized water) was obtained from a Milli-Q System (Millipore, Billerica, MA).

\section{Plant materials}

Plants used in this study included 14 wild herbaceous Paeonia accessions [P. lactiflora with two different colors (pink and white); P. obovata with two different colors (red and white); P. intermedia C.A. Meyer; P. anomala ssp. veitchii; $P$. anomala; P. mascula (L.) Miller; P. daurica ssp. wittmanniana (Hartwiss \& Lindley) D.Y. Hong; P. mlokosewitschii Lomakin; $P$. officinalis ssp. humilis (Retz.) Cullen \& Heywood; $P$. mascula ssp. russi (Biv.) Cullen \& Heywood; P. daurica Andrews; and P. tenuifolia], which originated from multiple locations (Fig. 1; Table 1) and a hybrid of wild herbaceous peony species with the code number H02222 ( $P$. daurica $\times P$. mascula). All plants were grown at the Chinese Academy of Sciences (lat. $39^{\circ} 48^{\prime} \mathrm{N}$, long. $116^{\circ} 28^{\prime} \mathrm{E}, 76 \mathrm{~m}$ altitude).

All petals at full bloom stage were collected from mid-April to the beginning of May in 2006 and 2007.

\section{Petal color measurement}

The colors of fresh petals were first identified according to the Royal Horticultural Society Color Chart [RHSCC (Royal Horticultural Society, 2001; Sakata et al., 1995)]. Petal color parameters in the middle portion of the upper epidermis were measured with a spectrophotometer NF333 (Nippon Denshoku

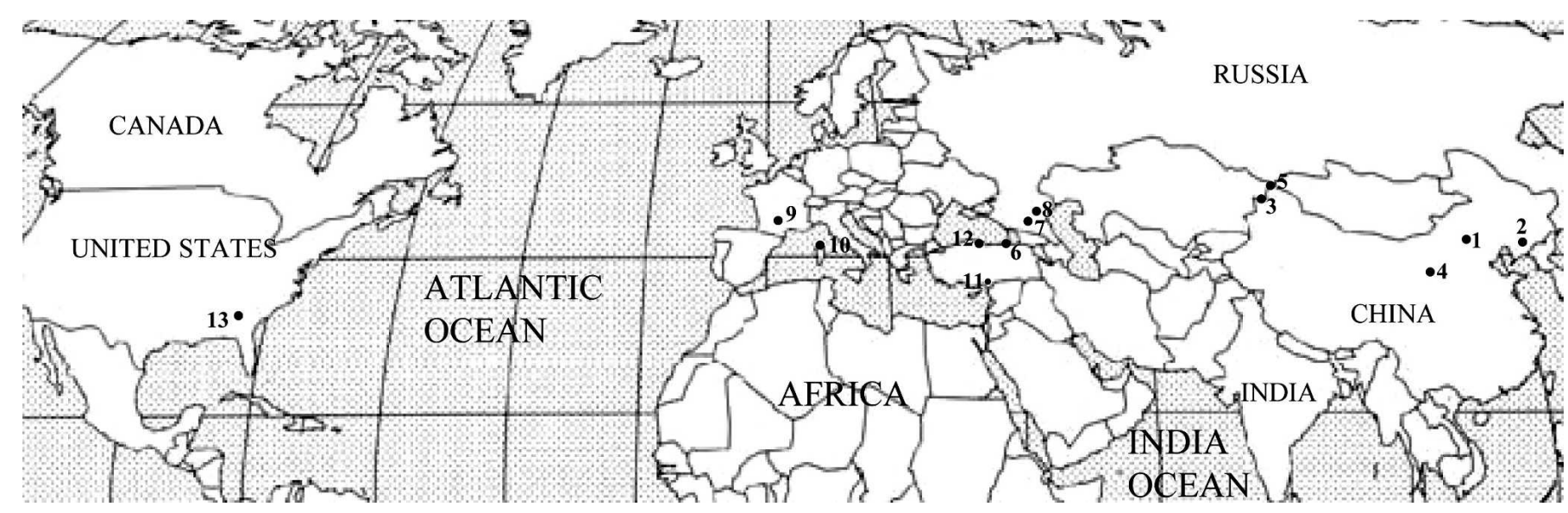

Fig. 1. The map illustrates the locations of nine herbaceous peony species (15 accessions) in the world. (1) Dahaituo National Nature Reserves, Chicheng County, Hebei Province, China; (2) Kuandian Manzu Minority Autonomous Region, Dandong City, Liaoning Province, China; (3) Tacheng Wild Almond Nature Reserve, Yumin County, Xinjiang Uygur Autonomous Region, China; (4) Lanzhou Peace Peony Garden, Yuzhong County, Gansu Province, China; (5) Kanas National Nature Reserve, Xinjiang Uygur Autonomous Region, China; (6) northern Turkey; (7) southern Caucasus region; (8) mideastern Caucasus region; (9) southern France; (10) La Corse, Mediterranean Sea; (11) Hatay, Turkey; (12) Amasya, Turkey; and (13) Kartli, Igoeti, GA. 
Table 1. Petal coloration of nine wild herbaceous peony species (15 accessions) in the genus Paeonia.

\begin{tabular}{|c|c|c|c|c|c|c|c|c|}
\hline \multirow[b]{2}{*}{ Species } & \multirow[b]{2}{*}{ RHSCC $^{z}$} & \multirow{2}{*}{$\begin{array}{c}\text { Color } \\
\text { series }^{\mathrm{y}}\end{array}$} & \multicolumn{5}{|c|}{ CIELab coordinates $^{x}$} & \multirow[b]{2}{*}{ Location $^{\mathrm{w}}$} \\
\hline & & & $\mathrm{L}^{*}$ & $\mathrm{a}^{*}$ & $\mathrm{~b}^{*}$ & $\mathrm{C}^{*}$ & $h$ & \\
\hline \multicolumn{9}{|l|}{ Chinese wild species } \\
\hline P. lactiflora (pink) & $78 \mathrm{D}$ & $\mathrm{P}$ & 63.9 & 8.6 & 1.9 & 8.8 & 12.2 & 1 \\
\hline P. obovata (red) & $71 \mathrm{D}$ & $\mathrm{RP}$ & 41.0 & 42.9 & -9.9 & 44.0 & -13.0 & 2 \\
\hline P. obovata (white) & $\mathrm{W}$ & $\mathrm{W}$ & 71.1 & -5.2 & 11.1 & 12.3 & 115.1 & 2 \\
\hline P. intermedia & $72 \mathrm{~A}$ & $\mathrm{RP}$ & 30.2 & 39.6 & -9.3 & 40.7 & -13.1 & 3 \\
\hline P. anomala & $72 \mathrm{~A}$ & $\mathrm{RP}$ & 38.1 & 38.2 & -15.1 & 41.0 & -21.8 & 5 \\
\hline \multicolumn{9}{|l|}{ European wild species } \\
\hline P. mascula & $64 \mathrm{~A}$ & $\mathrm{RP}$ & 34.9 & 42.7 & -3.8 & 42.8 & -5.1 & 6 \\
\hline P. daurica ssp. wittmanniana & $\mathrm{W}$ & $\mathrm{W}$ & 74.3 & -5.4 & 12.9 & 13.9 & 112.6 & 7 \\
\hline P. daurica ssp. wittmanniana (flares) & $70 \mathrm{C}$ & $P$ & 44.4 & 26.8 & -3.9 & 27.1 & -8.2 & 7 \\
\hline P. mlokosewitschii & $2 \mathrm{D}$ & $\mathrm{Y}$ & 92.6 & -15.3 & 23.5 & 28.0 & 123.1 & 8 \\
\hline P. daurica $\times$ P. mascula & $61 \mathrm{~A}$ & $\mathrm{RP}$ & 34.5 & 41.7 & -9.5 & 42.8 & -12.9 & 12 \\
\hline \multicolumn{9}{|l|}{ North American wild species } \\
\hline P. tenuifolia & $60 \mathrm{~A}$ & $\mathrm{R}$ & 31.5 & 41.5 & 9.4 & 42.6 & 12.8 & 13 \\
\hline
\end{tabular}

${ }^{\mathrm{z}}$ Royal Horticultural Society Colour Chart; W: white color.

${ }^{\mathrm{y}}$ Color series: P: pink series; W: white series; R: red series; RP: reddish purple series; Y: yellow series.

${ }^{x} L^{*}$ : Lightness; $a^{*}, b^{*}$ : chromatic components; $C^{*}$ : chroma; Hue angle $(h)=\arctan \left(b^{*} / a^{*}\right)$ (degree).

"Location: the explanation of the locations of nine species (15 accessions) were shown in Fig. 1.

Industries, Tokyo) at Commission Internationale de I'Eclairage (CIE) $\mathrm{C} / 2^{\circ}$ illumination/viewer condition. CIE made a method to measure and express the colors through value of $\mathrm{L}^{*}, \mathrm{a}^{*}$ and $b^{*}$. Within the CIELAB color coordinates, lightness $\left(\mathrm{L}^{*}\right)$ describes the lightness of the color, going from black $\left(\mathrm{L}^{*}=0\right)$ to perfect white $\left(\mathrm{L}^{*}=100\right)$; chromatic component $\mathrm{a}^{*}$ takes a positive value for reddish colors and a negative value for the greenish ones; chromatic component $b^{*}$ takes a positive value for yellowish colors and a negative value for the bluish ones (Gonnet, 1998). An average of five measurements was used. Chroma $\left(\mathrm{C}^{*}\right)$ and hue angle $(h)$ were calculated based on the following equations: $\mathrm{C}^{*}=\left(\mathrm{a}^{* 2}+\mathrm{b}^{* 2}\right)^{1 / 2}$ and $h=\tan ^{-1}\left(\mathrm{~b}^{*} / \mathrm{a}^{*}\right)$ (Gonnet, 1998; Gonnet and Hieu, 1992). After measuring the parameters of petal colors, the petals were dried in a FD-1T vacuum freeze dryer (Eastern Kingray Science and Technology, Beijing, China) at $-45{ }^{\circ} \mathrm{C}$ for $24 \mathrm{~h}$ and conserved in vacuum dryer until extraction.

\section{Sample extraction}

Petals of each sample [ $\approx 50$ to $100 \mathrm{mg}$ dry weight (DW)] were extracted with $5 \mathrm{~mL}$ of acidic methanol solution (70:27: 2 : 1; by volume, $\left.\mathrm{CH}_{3} \mathrm{OH}: \mathrm{H}_{2} \mathrm{O}: \mathrm{HCOOH}: \mathrm{CF}_{3} \mathrm{COOH}\right)$ in a test tube and shaken in a QL-861 vortex (Kylin-bell Laboratory Instruments, Jiangsu, China) at $4{ }^{\circ} \mathrm{C}$ for $24 \mathrm{~h}$ (Hashimoto et al., 2000). Extractions were filtered continuously with a filter paper $(15 \mathrm{~mm})$ and Millipore disk $(0.45 \mu \mathrm{m})$ before HPLC analysis. This experiment was performed three times for each sample.

High-performance liquid chromatography-diode array detection-electrospray ionization-mass spectrometry analysis of anthocyanins

QUALITATIVE HIGH-PERFORMANCE LIQUID CHROMATOGRAPHYDIODE ARRAY DETECTION ANALYSIS OF ANTHOCYANINS. Chromato- graphic analysis was carried out on a HPLC (Dionex, Sunnyvale, CA) equipped with a P680 HPLC Pump, thermostatted Column Compartment TCC-100, and a Dionex photodiode array detector, DAD-100. The HPLC column was TSK gel ODS-80Ts QA $(150 \times 4.6 \mathrm{~mm}$ i.d.) (Tosoh, Tokyo) and was protected with a Transgenomic CARB Sep Coregel 87C Guard Cartridge (Transgenomic, Omaha, NE). The temperature was set at $35^{\circ} \mathrm{C}$. Injection volume was $10 \mu \mathrm{L}$. Flow rate was $0.8 \mathrm{~mL} \cdot \mathrm{min}^{-1}$. The mobile phase consisted of $1.5 \%$ phosphoric acid water solution $\left[1.5 \mathrm{H}_{3} \mathrm{PO}_{4}: 98.5 \mathrm{H}_{2} \mathrm{O}(\mathrm{v} / \mathrm{v})\right]$ as solvent $\mathrm{A}$ and phosphoric acid/ formic acid/acetonitrile/water $\left[1.5 \mathrm{H}_{3} \mathrm{PO}_{4}: 20 \mathrm{HCOOH}: 25\right.$ $\mathrm{CH}_{3} \mathrm{CN}$ : $53.5 \mathrm{H}_{2} \mathrm{O}$ (by volume)] as solvent B (Sakata et al., 1995). The linear gradient was $20 \% \mathrm{~B}$ at $0 \mathrm{~min}, 70 \% \mathrm{~B}$ at $80 \mathrm{~min}$, and then returned to $20 \% \mathrm{~B}$ in $10 \mathrm{~min}$. Data were recorded on a computer with the Chromeleon software (Dionex). Chromatograms were acquired at 515 and $340 \mathrm{~nm}$ and photodiode array spectra were recorded between 200 to $800 \mathrm{~nm}$. Anthocyanins were primarily identified by comparison with the data, which were obtained from the authentic samples.

Each peak was identified clearly by HPLC-ESI-MS ${ }^{\mathrm{n}}$ (Agilent Technologies, Palo Alto, CA). The interface was an API electrospray (Agilent 1100 LC/MSD Trap VL) operating in positive ionization mode monitoring of the protonated molecular ions at the following operating conditions: gas $\left(\mathrm{N}_{2}\right)$ temperature $=350{ }^{\circ} \mathrm{C}$, flow rate $=6.0 \mathrm{~L} \cdot \mathrm{min}^{-1}$, nebulizer pressure $=241.3 \mathrm{kPa}$, octopole radiofrequency amplitude $=$ $150 \mathrm{~V}$, skim 1 voltage $=45.5 \mathrm{~V}$, skim 2 voltage $=6.0 \mathrm{~V}$, capillary exit $=123.9 \mathrm{~V}$, and cap exit offset $=78.4 \mathrm{~V}$. The temperature was set at $35{ }^{\circ} \mathrm{C}$. The flow rate was $0.8 \mathrm{~mL} \cdot \mathrm{min}^{-1}$ and the injection volume was $5 \mu \mathrm{L}$. The mobile phase was made up of solvent $\mathrm{A}(0.1 \%$ trifluoroacetic acid in water) and solvent $\mathrm{B}$ (acetonitrile). The gradient was $5 \% \mathrm{~B}$ at $0 \mathrm{~min}, 30 \% \mathrm{~B}$ at $40 \mathrm{~min}$, and then returned to $5 \% \mathrm{~B}$ in $10 \mathrm{~min}$. The ion trap mass 
spectrometer scanned from m/z 100 to 800 . The LC/MSD Trap software version 5.2 provided complete control over all instrumentation (Fu et al., 2006).

Semiquantitative analysis of total anthocyanins AND TOTAL FLAVONES AND FLAVONOLS. The amount of total anthocyanins [TA (milligrams per $100 \mathrm{mg}$ DW)] and total flavones and flavonols [TF (milligrams per $100 \mathrm{mg}$ DW)] were measured semiquantitatively from a simple linear regression using Mv3G5G for TA and rutin for TF as standards at 515 and 340 $\mathrm{nm}$, respectively. Copigmentation index (CI) was calculated by the formula: CI = TF/TA (Wang et al., 2001a, 2001b, 2004; Zhang et al., 2007, 2008).

\section{Statistical analysis}

Cluster analysis was performed using SPSS (version 13.0 for Windows; SPSS, Chicago). Hierarchical cluster analysis among 15 accessions was performed based on the squared Euclidean distance by SPSS considering the color parameters (i.e., $\mathrm{L}^{*} \mathrm{a}^{*}, \mathrm{~b}^{*}, \mathrm{C}^{*}$, and $h$ ), the content of individual anthocyanins [i.e., Pn3G5G, Pn3G5Ara, Pn3G, Cy3G5G, cyanidin 3-glucoside-5-galactoside (Cy3G5Gal), Cy3G, Pg3G5G, and pelargonidin 3-glucoside-5-galactoside (Pg3G5Gal)] (each relative percentage of total peak area), and TA and TF values as variables. The between-group linkage cluster method was used to calculate the distance of each cluster. The graphical representations were performed using Sigmaplot (version 10.0 for Windows; SPSS).

\section{Results}

\section{Identification of flower colors by CIELAB color coordinates}

RHSCC values of plain petals ranged from $2 \mathrm{D}$ (yellow) to $78 \mathrm{D}$ (pink), including white (Table 1). The flower colors of all the accessions were distributed on the CIELAB color coordinates: $\mathrm{L}^{*}=30.2$ in $P$. intermedia to 92.6 in $P$. mlokosewitschii, $\mathrm{a}^{*}=-15.3$ in $P$. mlokosewitschii to 44.3 in $P$. daurica, $\mathrm{b}^{*}=$ -15.1 in $P$. anomala to 23.5 in $P$. mlokosewitschii, $\mathrm{C}^{*}=8.8$ in pink $P$. lactiflora to 45.1 in $P$. daurica, and $h=-24.5$ in $P$. anomala ssp. veitchii to 132.7 in white P. lactiflora (Table 1). The color parameters of $P$. mlokosewitschii with yellow flowers was vastly different from other samples, and this characterization facilitated distinguishing it from other wild accessions (Figs. 2 and 3).

\section{Chromatographic anthocyanin identification}

HIGH-PERFORMANCE LIQUID CHROMATOGRAPHY-DIODE ARRAY DETECTION TOGETHER WITH HIGH-PERFORMANCE LIQUID CHROMATOGRAPHY-ELECTROSPRAY IONIZATION-MASS SPECTROMETRY ANALYSIS OF ANTHOCYANINS. Five major anthocyanins (Pn3G5G, Pn3G, Cy3G5G, Cy3G, Pg3G5G) captured at $515 \mathrm{~nm}$ were the same as those reported previously by Hosoki and Seo (1991). However, Pg3G, which was detected in trace amounts by Hosoki and Seo (1991), was not detected in our research. Three rare anthocyanins, including Cy3G5Gal (Fig. 4, peak 1), Pg3G5Gal (Fig. 4, peak 3), and Pn3G5Ara (Fig. 4, peak $6)$, were detected in wild herbaceous peony species and subspecies for the first time.

No shoulder at 290 to $340 \mathrm{~nm}$ was observed in the ultraviolet absorption spectra in peaks 1, 3, and 6; thus, it indicated that no aromatic acids were involved in (Fossen and Andersen, 1998). The position of attachment of the sugars of peaks 1,3 , and 6 were preliminarily identified by their

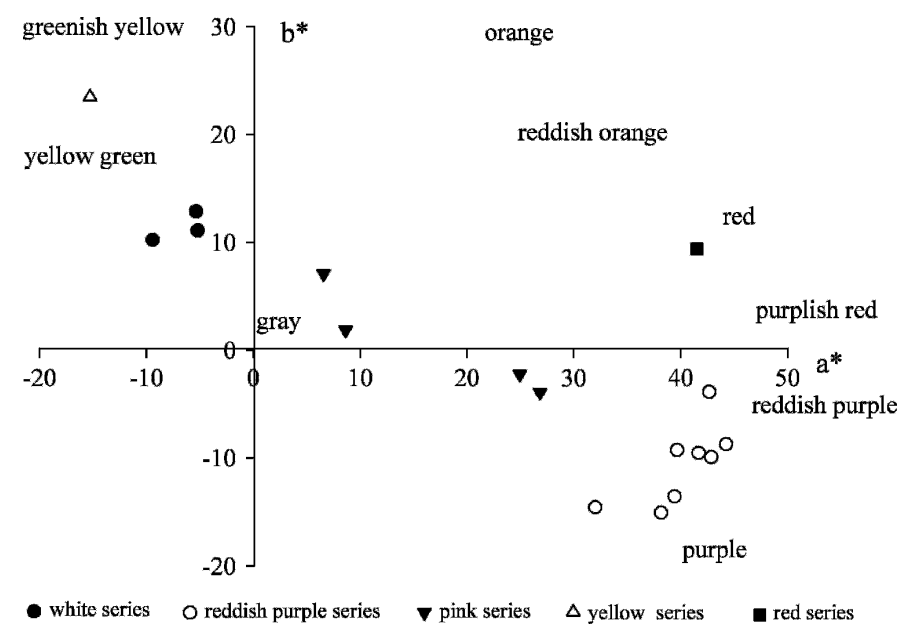

Fig. 2. Two-dimensional scattered picture of nine wild herbaceous peony species (15 accessions) in genus Paeonia based on the color parameters of $a^{*}$ and $b^{*}$.

ultraviolet-visible characteristic spectral properties (Harborne, 1958a, 1958b).

The absorption spectra did not have the distinct shoulder to the main absorption peak in the 410 to $450 \mathrm{~nm}$, which indicated that they contain sugars in the 5-position (Asen and Budin, 1966; Harborne, 1963). The ratio of absorption at $440 \mathrm{~nm}$ to the absorption at maximum visible absorption of three anthocyanins was calculated and compared with the control standards of tree peony (Tables 2 and 3). The results indicated that all anthocyanins contain sugars in both 3 - and 5-positions (Francis, 1982).

The chemical structure of anthocyanins was identified by comparison with the MS/MS data of the authentic samples. In the HPLC chromatograms of Chinese wild species, $P$. anomala and $P$. anomala ssp. veitchii (Fig. 4; Tables 2 and 3), peaks 1 and 2 , shared the same MS data $\left[(\mathrm{M})^{+} \mathrm{m} / \mathrm{z} 611, \mathrm{MS} / \mathrm{MS} \mathrm{m} / \mathrm{z}\right.$ 449, and 287 (cyanidin) $^{+}$]. Peaks 3 and 4 also shared the same MS data $\left[(\mathrm{M})^{+} \mathrm{m} / \mathrm{z}\right.$ 595, MS/MS m/z 433 and 271

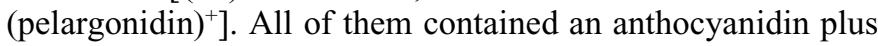

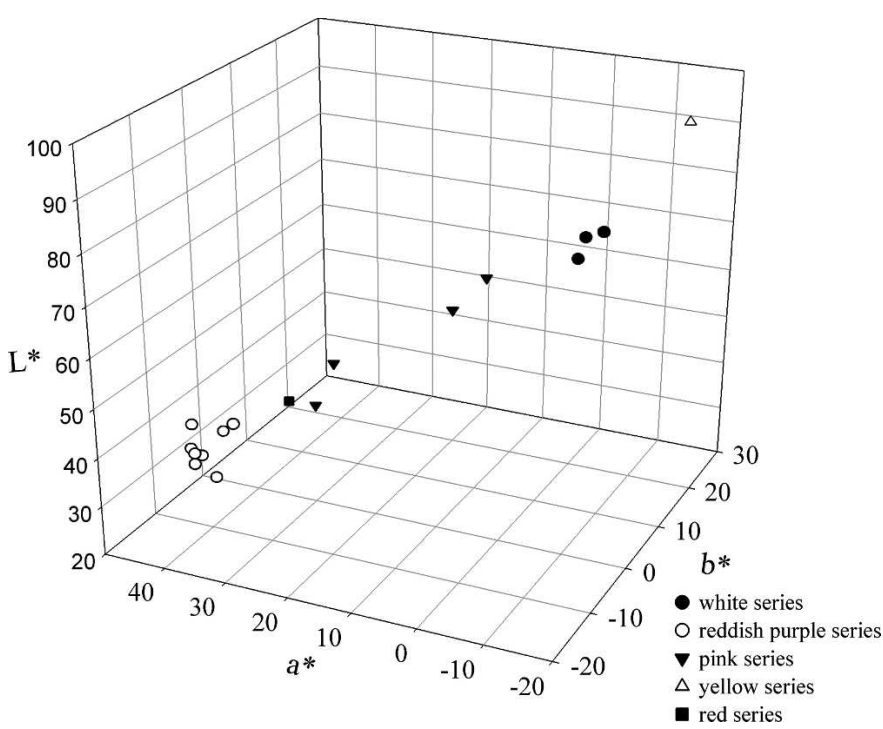

Fig. 3. Three-dimensional picture of nine wild herbaceous peony species (15 accessions) in genus Paeonia based on the color parameters of $\mathrm{L}^{*}, \mathrm{a}^{*}$, and $\mathrm{b}^{*}$. 
two hexoses. By comparing with the control standards of tree peony (Wang et al., 2001a), peaks 2 and 4 were identified as the 3,5-diglucosides of cyanidin and pelargonidin, respectively. Peaks 1 and 3 exhibited the same MS data as peaks 2 and 4 but shorter retention time (Tables 2 and 3). Considering the slight difference on retention time between them, peaks 1 and 3 should be two anthocyanins with higher polarity (Nicoué et al., 2007). Thus, peaks 1 and 3 were possibly considered to be Cy3G5Gal and Pg3G5Gal (Wu and Prior, 2005a, 2005b). However, the complete identification of chemical structure is now underway.

A unique peak (Fig. 4, peak 6) was detected from most European wild species and subspecies that was not detected in any Chinese accessions. Its ultraviolet-visible spectral chromatography showed the $\lambda_{\max }$ at $514.1 \mathrm{~nm}$, which was very close to those of Pn3G5G and Pn3G (513.5 and $515.5 \mathrm{~nm}$, respectively). It exhibited molecular ions at m/z 595 and a major fragment at

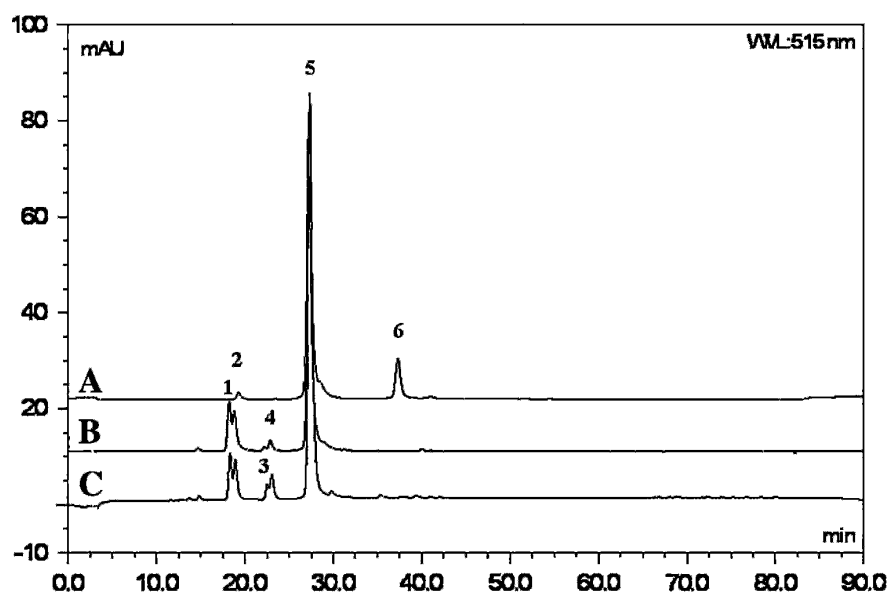

Fig. 4. Typical high-performance liquid chromatograms of anthocyanins in genus Paeonia captured at $515 \mathrm{~nm}$ : (A) P. daurica $\times$ P. mascula $(\mathrm{H} 02222)$, (B) $P$. anomala ssp. veitchii, (C) P. anomala. Peak identification is shown in Tables 2 and 3 . $\mathrm{m} / \mathrm{z} 301$, indicating it was a peonidin derivative. The MS/MS data $(\mathrm{m} / \mathrm{z} 463$ and 433$)$ showed the anthocyanin contained a hexose and a pentose. However, the ion abundance of $(\mathrm{M}-132)^{+}$ $(\mathrm{m} / \mathrm{z} 463)$ was larger than that of $(\mathrm{M}-162)^{+}(\mathrm{m} / \mathrm{z} 433)$. It indicated that the secondary ion mass spectrum of the anthocyanin was easy to lose $\mathrm{m} / \mathrm{z} 132$. Generally speaking, 3 - and 5hydroxyls in anthocyanidins are common glycosylation sites and 5-position of sugar was the most susceptive to break (Cuyckens and Claeys, 2004). Taking into account that arabinose is the common pentose found in nature (Da Silva et al., 2007), peak 6 was tentatively identified as Pn3G5Ara (Fig. 4; Tables 2 and 3), although nuclear magnetic resonance (NMR) spectroscopy or other analytical methods are needed to determine the exact chemical structure.

\section{Floral anthocyanin composition of nine wild herbaceous peony species (15 accessions)}

Two anthocyanidins, including Pn and $\mathrm{Cy}$, were detected in most accessions, whereas Pg was only observed in two Chinese species from Xinjiang Uygur Autonomous Region, China ( $P$. anomala and $P$. intermedia) and one subspecies (P. anomala ssp. veitchii) from Gansu Province, China (Table 4). All the accessions were the $\mathrm{Pn}>\mathrm{Cy}$ phenotype except for a vivid red species ( $P$. tenuifolia), which had a high proportion of $\mathrm{Cy}$ (89.4\%). No anthocyanidins were found in two white accessions ( $P$. obovata and $P$. daurica ssp. wittmanniana). Most accessions had a high proportion of Pn; in other words, the metabolic pathway of Pn dominated in herbaceous peony species.

The petal anthocyanin composition of Chinese species (seven accessions) was quite different from that of European species (seven accessions). For the Chinese species and subspecies, the distribution patterns of petal anthocyanins were quite simple. Pn3G5G and Cy3G5G were the major anthocyanins in most accessions except for $P$. intermedia, which had maximum anthocyanins, including Pn3G5G, Pn3G, Cy3G5G, Cy3G, and Pg3G5G. In European accessions, Pn3G5G, Pn3G5Ara, and Cy3G5G accounted for high proportions except

Table 2. Anthocyanins identified in the petals of Paeonia anomala ssp. veitchii, Paeonia anomala, and Paeonia daurica $\times$ Paeonia mascula (H02222).

\begin{tabular}{|c|c|c|c|c|c|c|c|c|}
\hline \multicolumn{2}{|c|}{ Peak } & \multicolumn{2}{|l|}{$\lambda_{\max }^{\mathrm{z}}$} & \multirow{2}{*}{$\begin{array}{c}\begin{array}{c}\mathrm{E}_{440} / \mathrm{E}_{\mathrm{vis}, \max } \\
(\%)^{\mathrm{z}}\end{array} \\
19.1 \pm 0.3\end{array}$} & \multirow{2}{*}{$\begin{array}{c}\begin{array}{c}\mathrm{M}^{+} \\
(\mathrm{m} / \mathrm{z})^{\mathrm{z}}\end{array} \\
611\end{array}$} & \multicolumn{2}{|c|}{$\mathrm{MS} / \mathrm{MS}(\mathrm{m} / \mathrm{z})^{\mathrm{z}}$} & \multirow{2}{*}{$\frac{\text { Identification }}{\text { Cyanidin-3-O-glucoside-5- } O \text {-galactoside }}$} \\
\hline 1 & $265.4 \pm 1.2$ & $512.3 \pm 0.3$ & & & & 449 & 287 & \\
\hline 2 & $277.1 \pm 0.8$ & $512.4 \pm 0.3$ & & $19.1 \pm 0.3$ & 611 & 449 & 287 & Cyanidin-3,5-di- $O$-glucoside \\
\hline 4 & $266.4 \pm 0.5$ & $273.2 \pm 0.3$ & $497.6 \pm 0.1$ & $26.6 \pm 0.2$ & 595 & 433 & 271 & Pelargonidin-3,5-di- $O$-glucoside \\
\hline 5 & $247.9 \pm 1.3$ & $277.0 \pm 0.3$ & $513.5 \pm 0.2$ & $18.0 \pm 0.1$ & 625 & 463 & 301 & Peonidin-3,5-di- $O$-glucoside \\
\hline 6 & $276.8 \pm 0.3$ & $514.1 \pm 0.6$ & & $17.8 \pm 0.1$ & 595 & 433 & 463 & Peonidin-3- $O$-glucoside-5- $O$-arabinoside \\
\hline
\end{tabular}

${ }_{\mathrm{z}} \lambda_{\max }=$ maximum absorption wavelength $(\mathrm{nm}) ; \mathrm{E}_{440}=$ the intensity at $440 \mathrm{~nm} ; \mathrm{E}_{\mathrm{vis}, \max }=$ the intensity at maximum visible absorption; $\mathrm{M}^{+}=$ molecular ion; $\mathrm{MS} / \mathrm{MS}=$ fragment ions of secondary ion mass spectrum.

Table 3. Spectral characteristics and mass spectral data of the control standards identified from Chinese tree peony cultivar Qing Long Wo Mo Chi and Japanese tree peony cultivar Hohki. ${ }^{z}$

\begin{tabular}{|c|c|c|c|c|c|c|c|c|}
\hline \multirow{2}{*}{$\frac{\text { Peak }}{2}$} & & \multirow{2}{*}{$\frac{\lambda_{\max }^{\mathrm{y}}}{512.5}$} & & \multirow{2}{*}{$\frac{\mathrm{E}_{440} / \mathrm{E}_{\mathrm{vis}, \max }(\%)^{\mathrm{y}}}{19.1}$} & \multirow{2}{*}{$\frac{\mathrm{M}^{+}(\mathrm{m} / \mathrm{z})^{\mathrm{y}}}{611}$} & \multicolumn{2}{|c|}{$\mathrm{MS} / \mathrm{MS}(\mathrm{m} / \mathrm{z})^{\mathrm{y}}$} & \multirow{2}{*}{$\frac{\text { Identification }}{\text { Cyanidin-3,5-di- } O \text {-glucoside }}$} \\
\hline & 276.9 & & & & & \multicolumn{2}{|c|}{$449 \quad 287$} & \\
\hline 4 & 266.8 & 273.2 & 497.6 & 26.6 & 595 & 433 & 271 & Pelargonidin-3,5-di- $O$-glucoside \\
\hline 5 & 247.9 & 277.2 & 513.5 & 18.0 & 625 & 463 & 301 & Peonidin-3,5-di- $O$-glucoside \\
\hline
\end{tabular}

${ }^{\mathrm{z}}$ Wang et al., 2001a; Zhang et al., 2007.

${ }^{\mathrm{y}} \lambda_{\max }=$ maximum absorption wavelength $(\mathrm{nm}) ; \mathrm{E}_{440}=$ the intensity at $440 \mathrm{~nm} ; \mathrm{E}_{\mathrm{vis}, \max }=$ the intensity at maximum visible absorption; $\mathrm{M}^{+}=$ molecular ion; MS/MS = fragment ions of secondary ion mass spectrum. 


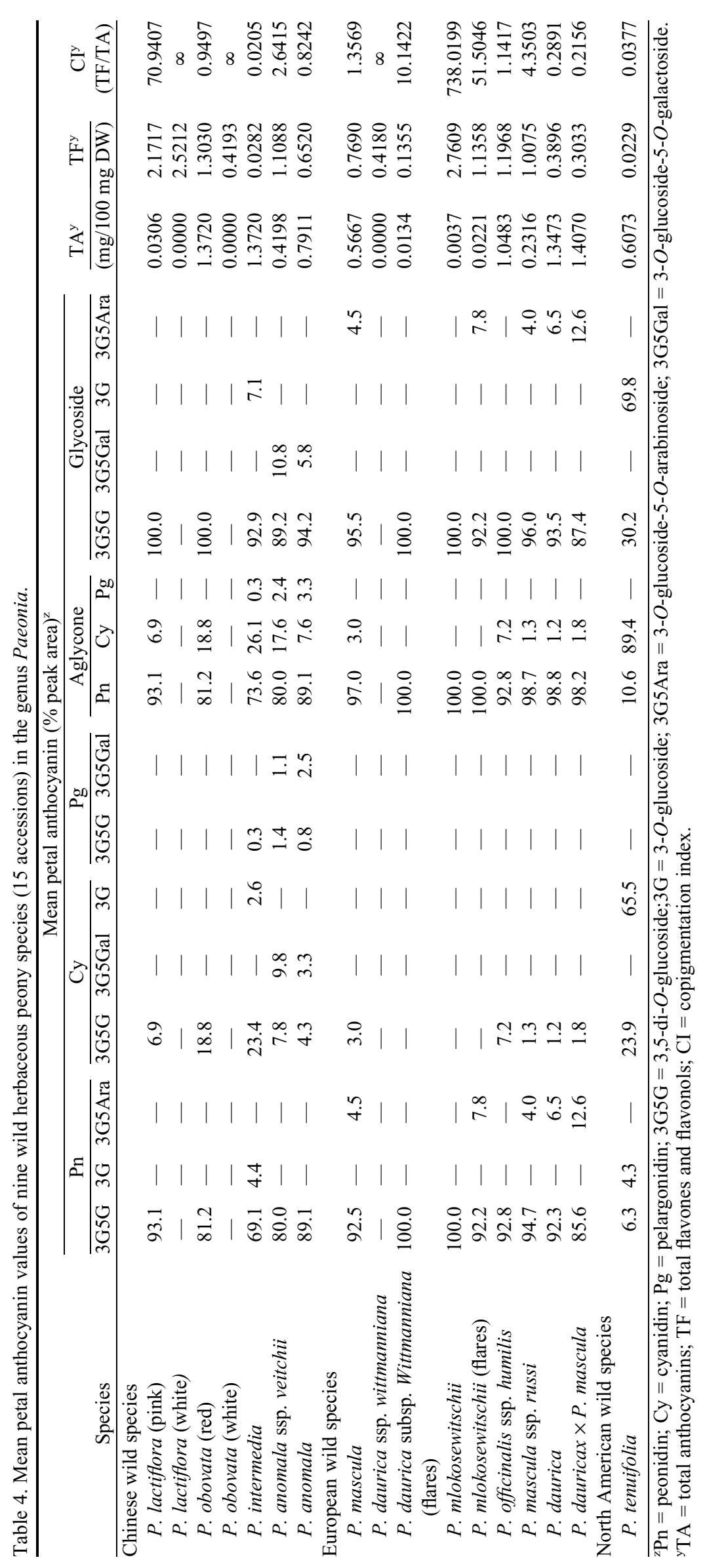


for $P$. officinalis ssp. humilis and $P$. daurica ssp. wittmanniana, which contained no Pn3G5Ara in petals at all. On the contrary, the North American species $P$. tenuifolia had a different anthocyanin composition. Although Pn3G5Ara was not observed, Cy3G and Pn3G were clearly detected in this species.

Paeonia mlokosewitschii and $P$. daurica ssp. wittmanniana (Hong and Zhou, 2003) had red flares on the base of petals, which made them double-colored petals. Paeonia mlokosewitschii was a yellow-flowered species with red veins on the edge of petals, whereas the main color of $P$. daurica ssp. wittmanniana was white and no anthocyanin was detected in its petals. Although both the flare colors and TA values $(0.0221 \mathrm{mg} / 100$ $\mathrm{mg}$ in P. mlokosewitschii; $0.0134 \mathrm{mg} / 100 \mathrm{mg}$ in $P$. daurica ssp. wittmanniana) of the two accessions were quite similar, there were some slight differences in the anthocyanin composition of the flares. Anthocyanins in the flares of $P$. mlokosewitschii were Pn3G5G and Pn3G5Ara, whereas only Pn3G5G was detected in $P$. daurica ssp. wittmanniana's flares. Anthocyanins of both flares were peonidin types, indicating similar biosynthetic pathways.

Cluster analysis. Paeonia mlokosewitschii and P. daurica ssp. wittmanniana belonged to the double color series. Although both of them had clear red flares on the base of the petals, the major colors were yellow and white, respectively. As a result, only the anthocyanins from yellow and white parts were used for principal component analysis (PCA).

Five clusters (1, 2, 3, 4, and 5) were derived (Fig. 5). Each sample cluster had the same flower color and similar anthocyanin composition. Cluster 1 consisted of three white accessions, all of which had no anthocyanin in the petals. Cluster 2 consisted of one yellow species, P. mlokosewitschii, which contained only Pn3G5G in the red veins of petals. Cluster 3 consisted of eight accessions with a reddish purple color. The total anthocyanins amount of each accession in this cluster was relatively high, ranging from $0.4198 \mathrm{mg} / 100 \mathrm{mg} \mathrm{DW}$ in $P$. anomala ssp. veitchii

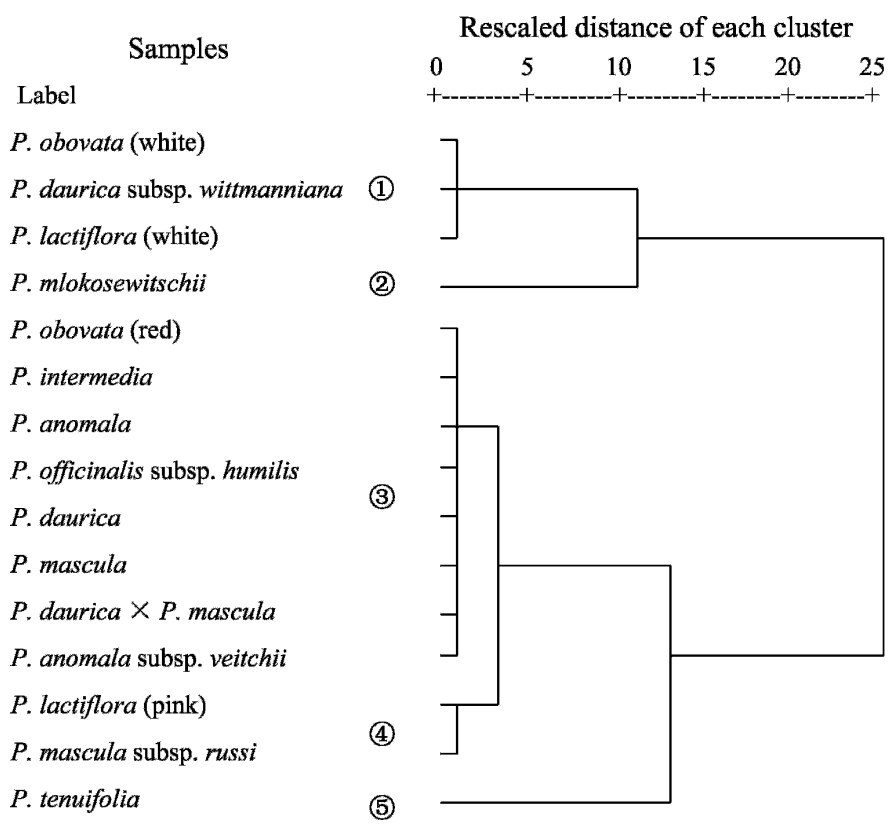

Fig. 5. Dendrogram of nine wild herbaceous peony species (15 accessions) in genus Paeonia by hierarchical cluster analysis. The cluster analysis was performed based on the Squared Euclidean distance by SPSS (version 13.0 for Windows; SPSS, Chicago, IL). to $1.4070 \mathrm{mg} / 100 \mathrm{mg} \mathrm{DW}$ in $P$. daurica $\times$ P. mascula (Table 4). Cluster 4 consisted of two pink accessions, including $P$. lactiflora (pink) and P. mascula ssp. russi. Cy3G5G and Pn3G5G were the main anthocyanins in this cluster. The TA value was very low compared with cluster 3 . Cluster 5 was composed of one red species, $P$. tenuifolia, and its anthocyanin composition was far different from those of other accessions.

\section{Discussion}

\section{Anthocyanin composition of four \\ Chinese wild species (seven accessions)}

The anthocyanin composition of Chinese wild herbaceous peony species was very simple. A majority of accessions in this study only had Pn3G5G and Cy3G5G. Pg3G5G was only detected in $P$. intermedia and $P$. anomala, the exclusive wild species from Xinjiang Uygur Autonomous Region (Hong et al., 1994), and $P$. anomala ssp. veitchii from Gansu Province, China (Hong and Pan, 2004). The different distribution patterns of anthocyanins indicated different biosynthetic and metabolic pathways between wild species from Xinjiang Uygur Autonomous Region and those from other places in China. There were no pelargonidin types of anthocyanins detected in most accessions except for the three accessions mentioned previously. It indicated that the enzyme flavonoid $3^{\prime}$-hydroxylase $\left(\mathrm{F} 3^{\prime} \mathrm{H}\right)$ was more competitive in the use of substrate than dihydroflavonol 4reductase. $\mathrm{F}^{\prime} \mathrm{H}$ catalyzed naringenin directly to synthesize eriodictyol and prevented the synthesis of dihydrokaempferol and sequentially interrupted the pathway of $\mathrm{Pg}$ synthesis (Nakayama et al., 1997; Schwinn et al., 1994).

Based on the original taxonomy of Paeonia, section Paeonia (Paeoniaceae), P. anomala in Xinjiang Uygur Autonomous Region, and $P$. veitchii Lynch in Gansu Province, China, were classified into two different species (Guo, 2002). However, Hong et al. (2001) made a taxonomic revision of Paeonia. $P$. veitchii was treated as the subspecies of $P$. anomala, namely $P$. anomala ssp. veitchii, for their similar blooming characteristics and variation in leaf shape and hairs on carpels among samples (Hong and Pan, 2004). According to our study of the anthocyanin compositions of these two accessions, we supported this revision because the unique anthocyanins of Cy3G5Gal (Fig. 4, peak 1) and Pg3G5Gal (Fig. 4, peak 3) had been detected in $P$. anomala and $P$. anomala ssp. veitchii indicating they belong to the same taxon.

\section{Anthocyanin composition of four \\ European wild species (seven accessions)}

A new anthocyanin, Pn3G5Ara, was detected in European wild species (five accessions). However, it was not detected in any Chinese species and subspecies. According to the evolutional theory of anthocyanins in previous research (Harborne, 1977), angiosperms in different climate areas have different anthocyanin metabolic pathways. Pelargonidin types only have appeared in very advanced tropical angiosperm families, whereas delphinidin types have occurred in temperate climates producing the delphinidin colors common in bee-pollinated families (Cooper-Driver, 2001; Zhao et al., 2005). Therefore, we assumed that the difference of anthocyanin composition between Chinese and European species may be caused by their different habitats and climatic types between the two zones, although further research is needed to study the evolutional difference of structures and sugars. 
The morphological characters of $P$. daurica and $P$. mascula were similar. Recently, the discrimination of these two species had been determined by Hong et al. (2007). Paeonia daurica was shown to be clearly differentiated from $P$. mascula in the number of leaflets of the lower leaves. In 21 May 2002, Hong et al. (2007) found a special sample coded H02222 ( $P$. daurica $\times$ P. mascula) in Amasya, Ladik, to Tasova, Turkey $(985 \mathrm{~m}$ altitude). All characteristics showed it was similar to that of $P$. daurica except for the number of leaflets. Although most leaflet numbers were nine, there remained an exception of 10 . This phenomenon was not consistent with $P$. daurica, which consistently had nine leaflets. Considering its location in a sympatric region of the two species, Hong et al. (2007) inferred it to be a hybrid between $P$. daurica and $P$. mascula $(P$. daurica $\times P$. mascula) because it closely resembled $P$. daurica. In our study, we found the anthocyanin compositions of $P$. daurica, $P$. mascula, and $\mathrm{H} 02222$ ( $P$. daurica $\times P$. mascula) were identical except for total anthocyanin amount (Table 4). To verify if H02222 was from hybridization, we made an intersectional cross $(P$. daurica $\times P$. mascula $)$ and a reverse intersectional cross $(P$. mascula $\times P$. daurica) in Apr. 2007 and obtained the resultant seeds. Results validated the cross-compatibility between $P$. daurica and $P$. mascula, although more information of these crosses should be observed and studied in the future.

\section{Comparison on anthocyanin composition}

between herbaceous peony and tree peony

The tree peony and herbaceous peony belong to the same genus. They are partly similar in morphological, chiefly in the flower forms and colors. However, based on our investigation and measurements of flower colors, we found herbaceous peony lacks real vivid red color as compared with that of tree peony. Compared with the anthocyanin composition of tree peony, the most remarkable characteristic of herbaceous peony was that no $\mathrm{Pg} 3 \mathrm{G}$ was detected in the petals. In addition, Pn3G5Ara, Cy3G5Gal, and Pg3G5Gal were unique anthocyanins in herbaceous peony. Based on our results, the mechanism of the formation of vivid red flower was quite different from tree peony to herbaceous peony, although the anthocyanin composition of them was similar. Hosoki et al. (1991) and Wang et al. (2001a) found that wild tree peony species lacked $\mathrm{Pg} 3 \mathrm{G}$, whereas Japanese vivid red cultivars lacked Cy3G and Cy3G5G but contained a large amount of Pg3G and Pg3G5G. Therefore, they assumed that the absence of Pg3G might be the reason for the shortage of red-flowered tree peony in China. Nevertheless, in herbaceous peony, we fortunately found a red wild species, $P$. tenuifolia, which had an obviously different anthocyanin composition. In general, Pn3G5G and Cy3G5G were the main anthocyanins in herbaceous peony and most accessions belonged to the $\mathrm{Pn}>\mathrm{Cy}$ phenotype. The content of $3 \mathrm{G}$-type pigments was much lower than that of 3G5G type. $P$. tenuifolia belonged to the $\mathrm{Cy}>\mathrm{Pn}$ phenotype and the contents of $\mathrm{Cy} 3 \mathrm{G}$ and $\mathrm{Cy} 3 \mathrm{G} 5 \mathrm{G}$ were up to $65.5 \%$ and $23.9 \%$, respectively. The content of $3 \mathrm{G}$ type $(69.8 \%)$ was much higher than that of 3 G5G type $(30.2 \%)$. The anthocyanin composition of $P$. tenuifolia was opposite to that of Japanese red tree peony cultivars. In other words, the former lacked Pg3G and Pg3G5G but contained a large amount of $\mathrm{Cy} 3 \mathrm{G}$ and $\mathrm{Cy} 3 \mathrm{G} 5 \mathrm{G}$ in the petals. Taking into account that high content of $\mathrm{Cy} 3 \mathrm{G}$ is responsible for the vivid red coloration of many red flowers such as Camellia japonica L. (Sakata, 1988), we hypothesized that the absence of $\mathrm{Cy} 3 \mathrm{G}$ in the petals might be the reason for the shortage of red-flowered herbaceous peony, although more samples should be examined to verify this conclusion.

\section{The correlations between flower colors and different factors}

Considering the anthocyanin compositions of all the species of herbaceous peony, we found that glycosylation and methylation were two major factors that influence flower colors.

Copigmentation effects, which were expected to occur when the TF/TA ratio exceeded 5 (Asen et al., 1971), were not observed in most herbaceous peony species (Table 4). As a result, copigmentation effect was not an important factor to influence the flower color of herbaceous peony. However, it is well known that petal colors are affected by many different factors. There is a lot of literature (Cooper-Driver, 2001) about the color characteristics of flowers in different species and different factors affecting the colors [ $\mathrm{pH}$, glycosylation, acylation, copigmentation, self-association, environment factors (light, temperature, soil, and so on)]. In general, the anthocyanins are mainly affected by the genetic factors, but the environmental factors have also certain effects. So further investigations are needed to make clear how different anthocyanins affect the final colors and the correlations between flower colors and various environment factors.

\section{Literature Cited}

Asen, S. and P.S. Budin. 1966. Cyanidin 3-arabinoside-5-glucoside, an anthocyanin with a new glycosidic pattern, from flowers of 'Red Wing' azaleas. Phytochemistry 5:1257-1261.

Asen, S., R.N. Stewart, and K.H. Norris. 1971. Co-pigmentation effect of quercetin glycosides on absorption characteristics of cyanidin glycosides and color of Red Wing azalea. Phytochemistry 10:171-175.

Chirinos, R., D. Campos, I. Betalleluz, M.M. Giusti, S.J. Schwartz, Q. Tian, R. Pedreschi, and Y. Larondelle. 2006. High-performance liquid chromatography with photodiode array detection (HPLCDAD)/HPLC-mass spectrometry (MS) profiling of anthocyanins from Andean mashua tubers (Tropaeolum tuberosum Ruiz and Pavón) and their contribution to the overall antioxidant activity. J. Agr. Food Chem. 54:7089-7097.

Cooper-Driver, G.A. 2001. Contributions of Jeffrey Harborne and coworkers to the study of anthocyanins. Phytochemistry 56:229-236.

Cuyckens, F. and M. Claeys. 2004. Mass spectrometry in the structural analysis of flavonoids. J. Mass Spectrom. 39:1-15.

Da Silva, F.L., M.T. Escribano-Bailón, J.J.P. Alonso, J.C. RivasGonzalo, and C. Santos-Buelga. 2007. Anthocyanin pigments in strawberry. LWT-Food Sci. Technol. 40:374-382.

Ferguson, D. and T. Sang. 2001. Speciation through homoploid hybridization between allotetraploids in peonies (Paeonia). Proc. Natl. Acad. Sci. USA 98:3915-3919.

Fossen, T. and O.M. Andersen. 1998. Cyanidin 3-O-(6"-succinyl$\beta$-glucopyranoside) and other anthocyanins from phragmites australis. Phytochemistry 49:1065-1068.

Francis, F.J. 1982. Analysis of anthocyanins, p. 181-207. In: Markakis, P. (ed.). Anthocyanins as food colors. Academic Press, New York, NY.

Fu, C.X., Y.J. Xu, D.X. Zhao, and F.S. Ma. 2006. A comparison between hairy root cultures and wild plants of Saussurea involucrata in phenylpropanoids production. Plant Cell Rpt. 24:750-754.

Gao, Z.M. and Z.H. Peng. 2004. On the industrialization of Chinese peony industry and sustainable development [in Chinese]. World For. Res. 17:45-48.

Gonnet, J.F. 1998. Colour effects of co-pigmentation of anthocyanins revisited-1. A colorimetric definition using the CIELAB scale. Food Chem. 63:409-415.

Gonnet, J.F. and H. Hieu. 1992. In situ micro-spectrophotometric and micro-spectrocolorimetric investigation of vascular pigments in 
flowers of cultivars of carnation (Dianthus caryophyllus). J. Hort. Sci. 67:663-676.

Guo, X.F. 2002. Advances in classification of Chinese herbaceous peony [in Chinese]. J. Beijing For. Univ. 24:99-102.

Harborne, J.B. 1958a. Spectral methods of characterizing anthocyanins. Biochem. J. 70:22-28.

Harborne, J.B. 1958b. The chromatographic identification of anthocyanin pigments. J. Chromatogr. A. 1:473-488.

Harborne, J.B. 1963. Plant polyphenols IX. The glycosidic pattern of anthocyanin pigments. Phytochemistry 2:85-97.

Harborne, J.B. 1977. Flavonoids and the evolution of the angiosperms. Biochem. Syst. Ecol. 5:7-22.

Hashimoto, F., M. Tanaka, H. Maeda, K. Shimizu, and Y. Sakata. 2000. Characterization of cyanic flower color of Delphinium cultivars. J. Jpn. Soc. Hort. Sci. 69:428-434.

Hong, D.Y. and K.Y. Pan. 2004. A taxonomic revision of the Paeonia anomala complex (Paeoniaceae). Ann. Missouri Bot. Garden 91:87-98.

Hong, D.Y., K.Y. Pan, and X.Y. Li. 1994. Paeonia in Xinjiang, China [in Chinese]. Acta Phytotaxonomica Sinica 32:349-355.

Hong, D.Y., K.Y. Pan, and N.J. Turland. 2001. Paeoniaceae, p. 127132. In: Wu, Z.Y., P.H. Raven, and D.Y. Hong (eds.). Flora of China. Vol. 6. Science Press, Beijing and Missouri Botanical Garden Press, St. Louis, MO.

Hong, D.Y., X.Q. Wang, D.M. Zhang, and S.T. Koruklu. 2007. Paeonia daurica Andrews or P. mascula ssp. triternata (Pall. ex DC.) Stearn \& P. H. Davis (Paeoniaceae)? Bot. J. Linnean Soc. 154:1-11.

Hong, D.Y., Z.X. Zhang, and X.Y. Zhu. 1988. Study on the genus Paeonia (1)-report of karyotypes of some wild species in China [in Chinese]. Acta Phytotaxonomica Sinica 26:33-43.

Hong, D.Y. and S.L. Zhou. 2003. Paeonia (Paeoniaceae) in the Caucasus. Bot. J. Linnean Soc. 143:135-150.

Hosoki, T., M. Hamada, T. Kando, R. Moriwaki, and K. aba. 1991. Comparative study of anthocyanins in tree peony flowers. J. Jpn. Soc. Hort. Sci. 60:395-403.

Hosoki, T. and M. Seo. 1991. Flower anthocyanins of herbaceous peony. Bul. Fac. Agr. Shimane Univ. 25:11-14.

Li, J.J. 1999. Appendix 1: Name list of Chinese tree peony and herbaceous peony cultivars, p. 242-243. In: Li, J.J. (ed.). Chinese tree peony and herbaceous peony [in Chinese]. China Forestry Publishing House, Beijing, China.

Montoro, P., C.I.G. Tuberoso, A. Perrone, S. Piacente, P. Cabras, and C. Pizza. 2006. Characterisation by liquid chromatography-electrospray tandem mass spectrometry of anthocyanins in extracts of Myrtus communis L. berries used for the preparation of myrtle liqueur. J. Chromatogr. A. 1112:232-240.

Nakayama, M., M. Koshioka, M. Shibata, S. Hiradate, H. Sugie, and M. Yamaguchi. 1997. Identification of cyanidin 3-O-(3",6" -betadimalonyl-beta-glucopyranoside) as a flower pigment of chrysanthemum (Dendranthema grandiflorum). Biosci. Biotechnol. Biochem. 61:1607-1608.

Nicoué, E.É., S. Savard, and K. Belkacemi. 2007. Anthocyanins in wild blueberries of Quebec: Extraction and identification. J. Agr. Food Chem. 55:5626-5635.

Pan, K.Y. 1995. The analysis of distribution pattern in the Paeoniaceae and its formation [in Chinese]. Acta Phytotaxonomica Sinica 53:340-349.

Peng, Z.H. and S.H. Jiang. 2000. Distinctive characters and origin of Paeoniaceae [in Chinese]. J. Anhui Agr. Univ. 27:209-213.

Royal Horticultural Society. 2001. Royal Horticultural Society colour chart. In: British Colour Council (ed.). Royal Horticultural Society, London, UK.

Sakata, Y. 1988. Studies on the flower colours in the genus Camellia, with special reference to the phylogenies of the genus [in Japanese]. Bul. Fac. Agr. Kagoshima Univ. 38:9-62.
Sakata, Y., N. Aoki, S. Tsunematsu, H. Nishikouri, and T. Johjima. 1995. Petal coloration and pigmentation of tree peony bred and selected in Daikon Island (Shimane Prefecture). J. Jpn. Soc. Hort. Sci. 64:351-357.

Sang, T., D.J. Crawford, and T.F. Stuessy. 1997. Chloroplast DNA phylogeny, reticulate evolution, and biogeography of Paeonia (Paeoniaceae). Amer. J. Bot. 84:1120-1136.

Schwinn, K.E., K.R. Markham, and N.K. Given. 1994. Floral flavonoids and the potential for pelargonidin biosynthesis in commercial Chrysanthemum cultivars. Phytochemistry 35:145-150.

Stern, F.C. 1946. A study of the genus Paeonia. Royal Horticultural Society, London, UK.

Wang, J.G. 2003. Green herbaceous peony had been bred by a horticulturist from Heze [in Chinese]. China Flowers Hort. 17:27.

Wang, J.G. and Z.S. Zhang. 2005. Cultivation and propagation, p. 17. In: Wang, J.G. and Z.S. Zhang (eds.). Herbaceous peonies of China [in Chinese]. China Forestry Publishing House, Beijing, China.

Wang, L.S., F. Hashimoto, A. Shiraishi, N. Aoki, J.J. Li, and Y. Sakata. 2004. Chemical taxonomy of the Xibei tree peony from China by floral pigmentation. J. Plant Res. 117:47-55.

Wang, L.S., A. Shiraishi, F. Hashimoto, N. Aoki, K. Shimizu, and Y. Sakata. 2001a. Analysis of petal anthocyanins to investigate flower coloration of Zhongyuan (Chinese) and Daikon Island (Japanese) tree peony cultivars. J. Plant Res. 114:33-43.

Wang, L.S., F. Hashimoto, A. Shiraishi, N. Aoki, J.J. Li, K. Shimizu, and Y. Sakata. 2001b. Phenetics in tree peony species from China by flower pigment cluster analysis. J. Plant Res. 114:213-221.

Wister, J.C. and H.E. Wolfe. 1962. Histories of the herbaceous peonies, p. 33-61. In: Wister, J.C. (ed.). The peonies. Amer. Hort. Soc., Washington, DC.

$\mathrm{Wu}, \mathrm{X}$. and R.L. Prior. 2005a. Identification and characterization of anthocyanins by high-performance liquid chromatography-electrospray ionization-tandem mass spectrometry in common foods in the United States: Vegetables, nuts, and grains. J. Agr. Food Chem. 53:3101-3113.

Wu, X. and R.L. Prior. 2005b. Systematic identification and characterization of anthocyanins by HPLC-ESI-MS/MS in common foods in the United States: Fruits and berries. J. Agr. Food Chem. 53:25892599.

Yu, J. and P.G. Xiao. 1987. A preliminary study on the chemistry and systematics of Paeoniaceae [in Chinese]. Acta Phytotaxonomica Sinica 25:172-179.

Yuan, T. 1999. The germplasm resource of tree peony and herbaceous peony, p. 12. In: Wang, L.Y. and T Yuan (eds.). Chinese tree peony and herbaceous peony [in Chinese]. Golden Shield Press, Beijing, China.

Zhang, H.J. and Y.Y. Cheng. 2006. An HPLC/MS method for identifying major constituents in the hypocholesterolemic extracts of Chinese medicine formula 'Xue-Fu-Zhu-Yu decoction'. Biomed. Chromatogr. 20:821-826.

Zhang, J., L.S. Wang, J.M. Gao, Q.Y. Shu, C.H. Li, J. Yao, Q. Hao, and J.J. Zhang. 2008. Determination of anthocyanins and exploration of relationship between their composition and petal coloration in crape myrtle (Lagerstroemia hybrid). J. Integrative Plant Biol. (in press).

Zhang, J.J., L.S. Wang, Z.A. Liu, and C.H. Li. 2006. Recent advances in flower color research of tree peony [in Chinese]. Acta Hort. Sinica 33:1383-1388.

Zhang, J.J., L.S. Wang, Q.Y. Shu, Z.A. Liu, C.H. Li, J. Zhang, X.L. Wei, and D.K. Tian. 2007. Comparison of anthocyanins in nonblotches and blotches of the petals of Xibei tree peony. Scientia Hort. 114:104-111.

Zhao, C.L., W.M. Guo, and J.Y. Chen. 2005. Formation and regulation of flower color in higher plants [in Chinese]. Chinese Bul. Bot. 22:70-81. 